\title{
A Giant Hemorrhagic Adrenal Pseudocyst
}

\section{Case Report}

\author{
Goran Stimac $^{\mathrm{a}}$ Josip Katusic ${ }^{\mathrm{a}}$ Mario Sucic $^{\mathrm{a}}$ Mario Ledinsky ${ }^{\mathrm{b}}$ Bozo Kruslin ${ }^{\mathrm{c}}$ \\ Davor Trnski ${ }^{\mathrm{a}}$ \\ Departments of a Urology, ' Surgery and 'Pathology, 'Sestre milosrdnice' University Hospital, Zagreb, Croatia
}

\section{Key Words}

Adrenal gland $\cdot$ Hemorrhagic adrenal pseudocyst, treatment

\begin{abstract}
Objective: To report a rare case of a giant hemorrhagic adrenal pseudocyst and highlight the importance of this entity to clinicians. Case Presentation: A 57-year-old woman presented with a 1-year history of abdominal pain and distension. Ultrasonography and multislice computed tomography revealed a giant cystic (partially solid) mass over the left suprarenal region measuring $20 \times 17 \times 15 \mathrm{~cm}$. A complete endocrine workup failed to detect any hormonal hypersecretion. Intervention: The patient was treated with tumor excision through transabdominal pararectal approach. Histopathological examination revealed a hemorrhagic adrenal pseudocyst. Conclusion: To our knowledge the case presented here appears to be one of the largest hemorrhagic adrenal pseudocysts reported so far. Radiological and clinical features of the tumor are nonspecific and histopathological examination is essential to establish definitive diagnosis. An open, laparotomic adrenalectomy is the preferred surgical technique for better control of such a large mass with active bleeding inside.
\end{abstract}

Copyright $\odot 2008$ S. Karger AG, Basel
(C) 2008 S. Karger AG, Basel

1011-7571/08/0175-0419\$24.50/0

Fax +4161306 1234

E-Mail karger@karger.ch

www.karger.com
Accessible online at: www.karger.com/mpp

\section{Introduction}

Cystic lesions of the adrenal gland are uncommon and demonstrate a spectrum of histological changes and may vary from pseudocysts to malignant cystic neoplasms. An adrenal pseudocyst is a fibrous-surrounded cyst within the adrenal gland devoid of a recognizable layer of lining cells. The incidence of adrenal hemorrhagic pseudocyst is very low. Less than 100 hemorrhagic pseudocysts have been reported, but only few of these had such giant proportions $[1,2]$. We report a case of giant adrenal pseudocyst measuring about $20 \mathrm{~cm}$ in largest diameter.

\section{Case Report}

A 57-year-old woman presented with a 1-year history of abdominal pain and distension. A left upper quadrant abdominal mass was palpated during examination. There was no history of hypertension or trauma in the past. The ultrasonographic examination of the abdominal mass showed a giant cystic mass over the left suprarenal region with internal echoes noted within the cyst. A multislice CT scan revealed a giant cystic (partially solid) mass measuring $20 \times 17 \times 15 \mathrm{~cm}$ and displacing the left kidney to the left lower quadrant of the abdomen (fig. 1). A complete endocrine workup including the estimation of urinary metanephrines, vanillylmandelic acid and free cortisol did not show any hormonal hypersecretion. The patient underwent surgery through upper medial transperitoneal approach and the tumor measuring about 


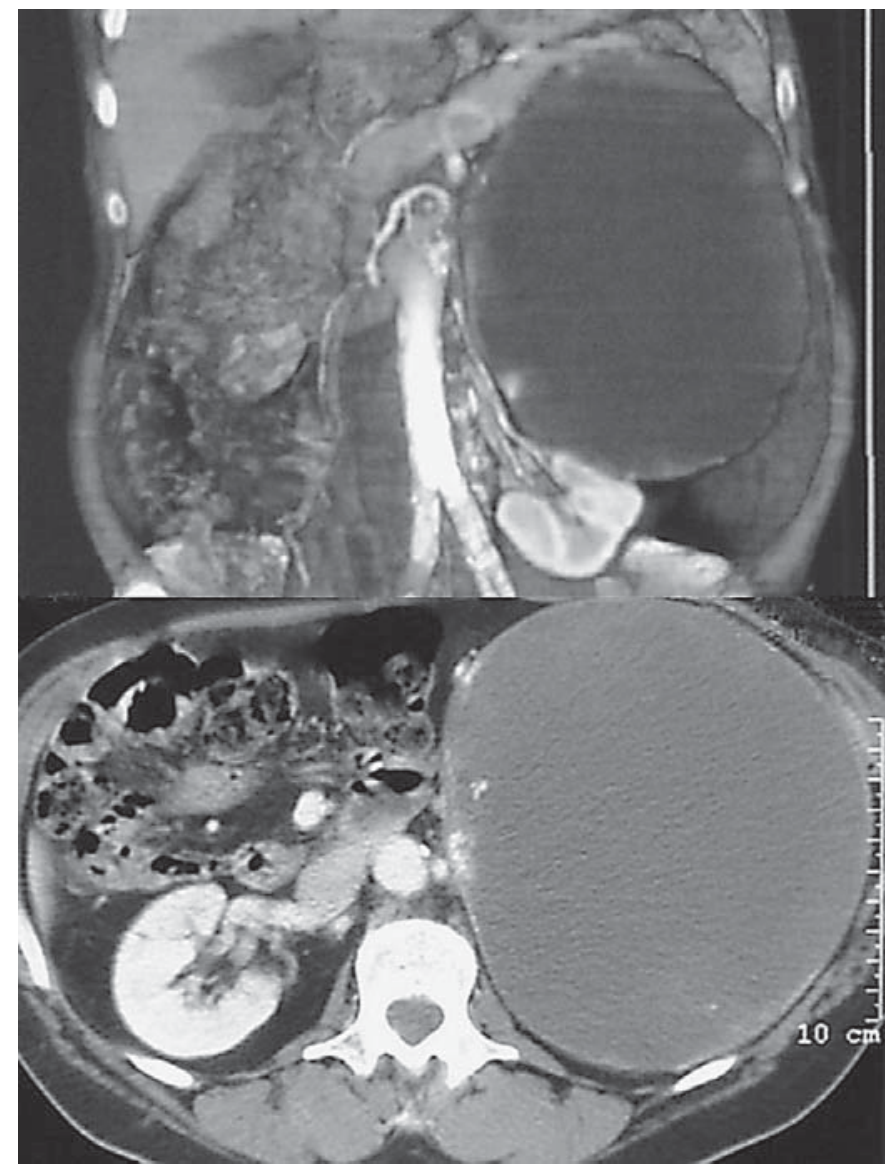

Fig. 1. Multislice CT image of the abdomen showing a giant cystic tumor with an egg shell-like appearance and calcification of walls in the mid and upper left abdomen extending to the upper pelvis and displacing the left kidney, measuring $20 \mathrm{~cm}$ in the largest diameter.

$20 \mathrm{~cm}$ in largest diameter was completely removed. It was located under the pancreatic body, splenic flexure of the transverse colon, and over the left kidney. It was separated from the adjacent organs without any difficulties. Histological examination showed that the cyst wall consisted of hyalinized fibrous tissue without an epithelial or endothelial lining and organized hematic content, and a diagnosis of an adrenal pseudocyst was made. Normal adrenal gland was forming part of its wall. Immunohistochemistry was CD 34-positive. The patient did well postoperatively, and her pain completely resolved.

\section{Discussion}

Adrenal gland cysts are uncommon entities and four pathological subtypes have been described: (1) cystic degeneration of adrenal neoplasms, (2) true cysts, (3) pseu- docysts and (4) infectious cysts [3]. Hemorrhagic pseudocysts are even rarer and probably occur secondary to adrenal hemorrhage. Cystic degeneration of adrenals with hemorrhage has previously been described in various malignant adrenal tumors $[4,5]$. The reported incidence of malignancy in adrenal cystic lesions was approximately $7 \%$ [6]. Among adrenal cysts the most common types are epithelial cysts and pseudocysts. True cysts are lined with endothelial or mesothelial cells [7]. On the contrary, adrenal pseudocysts are devoid of a recognizable lining layer and arise within the adrenal gland surrounded by a fibrous tissue wall. Infectious cysts are most commonly caused by Echinococcus [8]. Most of these cystic lesions are clinically silent and are therefore often diagnosed incidentally. Large cysts generally present as nonspecific abdominal pain and pose a differential diagnostic dilemma to the treating urologist. Since up to $7 \%$ of adrenal cysts are malignant, a careful preoperative hormonal, and morphofunctional evaluation is mandatory [9]. In particular, serum vanillylmandelic acid, adrenocorticotropic hormone and cortisol have to be investigated to rule out functioning adrenal carcinomas or pheochromocytoma. Most of the malignant adrenal cysts are metastatic (95\%), followed by pheochromocytoma (3\%) and adrenocortical carcinoma (2\%) [9]. Malignancy may be suspected in the presence of symptoms caused by functioning neoplasms such as Cushing's syndrome, hyperadrenalism, hirsutism in women, acne and balding in men, and hypertension. Our patient did not have any of these symptoms. Radiological workup (CT, MRI) plays a very helpful role in the localization of the origin, in determining the cystic nature and whether or not the retroperitoneal mass is benign. Density of the mass usually indicates a cystic nature. Both benign and malignant adrenal cysts may have calcification, egg shell-like in appearance, such as in our case. Fine-needle aspiration cytology as well as examination of a punch biopsy specimen of the cystic wall are of limited value, as there is considerable overlap in cytologic and histologic features of benign and malignant adrenal cystic lesions. Histopathology of the excised specimen gives confirmatory diagnosis. The pathogenesis is unclear. Hemorrhagic cystic degeneration resembling that of a thyroid nodule or malformation of an artery or a vein which undergoes cystic dilatation or hemorrhage have been proposed [3]. Predisposing factors for adrenal hemorrhage such as trauma to the abdomen, infection, anoxia in infants, hemorrhagic diathesis, embolism, and aneurysm are present in $32 \%$ of adrenal cysts [10]. Surgical excision is indicated in the presence of symptoms, suspicion of malignancy, increase in size or 
detection of a functioning adrenal cyst and can be managed by open surgery or laparoscopic approach [1]. Minimally invasive techniques are more effective for small tumors $[1,6]$. Kalady et al. [11] recommend that cysts larger than $6 \mathrm{~cm}$ should be approached using an open procedure because of concerns about potential malignancy. In case of giant pseudocysts, most authors prefer open adrenalectomy, since the laparoscopic approach is not sufficient to control such large masses with active bleeding inside.

\section{Conclusion}

A hemorrhagic adrenal pseudocyst is an uncommon clinical finding and it is even rarer when having such giant proportions. In most cases of hemorrhagic adrenal pseudocysts, no identifiable cause of hemorrhage can be determined. Surgery is required for symptomatic cases and in case of uncertain diagnosis. Radiological and clinical features of the tumor are nonspecific and histopathological examination is essential to establish definitive diagnosis. The operation is usually a laparotomic adrenalectomy for better control of such large masses.

\section{References}

-1 Amarillo HA, Bruzoni M, Loto M, Castagneto GH, Mihura ME: Hemorrhagic adrenal pseudocyst: laparoscopic treatment. Surg Endosc 2004;18:1539.

2 Rosai J: Adrenal gland and other paraganglia; in Ackerman LV, Rosai J: Surgical Pathology, ed 8. Saint Louis, Mosby, 1995, pp 1043-1044.

3 Medeiros LJ, Lewandrowski KB, Vickery AL Jr: Adrenal pseudocyst: a clinical and pathologic study of eight cases. Hum Pathol 1989; 20:660-665.

4 Weber T, Sotelo-Avila C, Gale G: Cystic neuroblastoma in a newborn. J Pediatr Surg 1993;28:1603-1604.
5 Munden R, Adams DB, Curry NS: Cystic pheochromocytoma: radiological diagnosis. South Med J 1993;86:1302-1305.

$\checkmark 6$ Khoda J, Hertzanu, Y, Sebbag G, Lantsberg L, Barky Y: Adrenal cysts: diagnosis and therapeutic approach. Int Surg 1993;78:239242.

$>7$ Fukushima N, Oonishi T, Yamaguchi K, Fukayama M: Mesothelial cyst of the adrenal gland. Pathol Int 1995;45:156-159.

8 Fitzgerald EJ: Hydatid disease of the adrenal gland. Ir J Med Sci 1987;156:366-367.
-9 Outwater E, Bankoff MS: Clinically significant adrenal hemorrhages secondary to metastases: computed tomographic observations. Clin Imaging 1989;13:195-200.

10 Scully RE, Mark EJ, McNeely WF, McNeely BU: Case records of the Massachusetts General Hospital: weekly clinicopathological exercises, case 15-1992. A 23-year-old woman with a painful mass in the right adrenal region. N Engl J Med 1992;326:1008-1015.

11 Kalady MF, McKinlay R, Olson JA Jr, Pinheiro J, Lagoo S, Park A, Eubanks WS: Laparoscopic adrenalectomy for pheochromocytoma: a comparison to aldosteronoma and incidentaloma. Surg Endosc 2004;18:621625. 